\title{
Autonomia feminina e concepções de direito entre mulheres beneficiárias do Programa Bolsa Família
}

\author{
Female autonomy and concepts of rights among women \\ beneficiaries of the Bolsa Família Program
}

Silvana Mariano*

Márcio Ferreira de Souza**

\begin{abstract}
Resumo - O presente artigo trata do tema da autonomia feminina e objetiva compreender a percepção de mulheres beneficiárias do Programa Bolsa Família em torno das concepções políticas como direito e cidadania. Para tanto, inferimos o modo como elas interpretam a relação com o Estado, o acesso às políticas públicas e o seu agenciamento nesse processo. Buscamos captar e dimensionar a autonomia dessas mulheres para a tomada de decisões no espaço doméstico e em aspectos relativos à individualização feminina, tanto no contexto das relações familiares como das relações sociais mais amplas. As análises foram calcadas em estudos de caso realizados em Curitiba (Paraná) e Fortaleza (Ceará), no ano de 2013, por meio de uma amostragem constituída por cento e noventa entrevistas, sendo noventa e cinco em cada cidade.

Palavras-chave: autonomia feminina; cidadania; espaço doméstico; Programa Bolsa Família.
\end{abstract}

\begin{abstract}
This article deals with the theme of female autonomy and aims to understand the perception of women beneficiaries of the Bolsa Família Program on political concepts such as rights and citizenship. In this way, we infer how they interpret the relationship with the state, access to public policies, and their agency in this process. We seek to capture and measure these women's autonomy for decision making in the domestic space and in aspects related to female individualization, both in the context of family relationships as well as broader social relations. The analyzes were based on case studies conducted in Curitiba (Paraná) and Fortaleza (Ceará), in 2013, through a sample consisting of one hundred and ninety interviews, ninety-five in each city.

Keywords: female autonomy; citizenship; domestic space; Bolsa Família Program.
\end{abstract}

\footnotetext{
* Doutora em Sociologia pela Universidade de Campinas (Unicamp). Professora do Departamento de Ciências Sociais e do Programa de Pós-Graduação em Sociologia da UEL. E-mail: silvanamariano@yahoo.com.br. ORCID: https://orcid.org/0000-0002-5849-9460.

**Doutor em Sociologia pela UFMG. Professor do Instituto de Ciências Sociais da UFU. Docente do Programa de Pós-Graduação em Sociologia da UEL. E-mail: marcfs@uol.com.br. ORCID: https://orcid.org/0000-0002-38821184.
} 


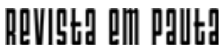

\} AUTONOMIA FEMININA E CONCEPÇÕES DE DIREITO - MARIANO, S.; SOUZA, M. F. \}

DOI: $10.12957 /$ REP.2019.45220

\section{Introdução ${ }^{1}$}

Os estudos sobre famílias e políticas sociais têm encontrado importantes contribuições advindas das pesquisas sobre as condições das mulheres em situação de pobreza ou de desproteção social. Essas investigações se apoiam em reflexões acerca da cidadania das mulheres e têm possibilitado um importante acúmulo para os estudos sobre desigualdades, especialmente desde a segunda metade do século XX, como também sobre os arranjos adotados pelas políticas sociais e seus possíveis efeitos para a cidadania das mulheres.

Essa vasta agenda de pesquisa, informada por perspectivas da sociologia da família e dos estudos de gênero e feministas, motiva investigações sobre a importância das mulheres para as políticas sociais e a importância das políticas sociais para as mulheres. Essas pesquisas exploram também as ambiguidades desta relação e, no caso latino-americano e brasileiro, problematizam em especial o caráter "familista" das políticas sociais e as tendências de inclusão instrumental das mulheres. Aderindo a esta agenda de pesquisas, nossa análise tem como ponto de partida duas noções interconectadas " cidadania e autonomia feminina " como expressão do empoderamento das mulheres, cujo pano de fundo é a relação entre gênero, democracia e políticas públicas.

A pesquisa teve como objetivo geral compreender as condições para a conquista de autonomia das mulheres pobres, por meio do Programa Bolsa Família (PBF), a partir dos recortes de gênero, raça/etnia e geração. Em um momento no qual o acesso ao consumo tende a concentrar os interesses das pesquisas com populações atendidas por políticas sociais, especialmente quando se trata de transferência de renda, nosso interesse é, diferentemente, orientado por preocupações como a ampliação das liberdades, da individualização e da politização dos direitos das mulheres.

As análises são desenvolvidas com base em estudos de caso realizados nos municípios de Curitiba (Paraná) e Fortaleza (Ceará), no ano de 2013. A amostragem completa da pesquisa é constituída por 190 entrevistas, sendo 95 em cada cidade, e o instrumento de coleta de dados foi um roteiro estruturado composto por perguntas fechadas e abertas. As perguntas abertas foram codificadas com base na análise de conteúdo e o conjunto de informações foi registrado em programa de análise estatística. As entrevistas foram realizadas em sedes dos Centros de Referência de Assistência Social (Cras).

As disparidades entre as duas capitais, observadas a partir dos principais indicadores socioeconômicos adotados pelos órgãos de pesquisa

\footnotetext{
1 Agradecemos ao CNPq, pelo financiamento do projeto de pesquisa intitulado Discriminação interseccional: estudos sobre situações de pobreza e empoderamento feminino entre mulheres titulares do Programa Bolsa Família no Paraná e no Ceará, e, também, à Maria Andrea Luz da Silva e à Maria Helena de Paula Frota, ambas da UECE, pela colaboração no trabalho de campo realizado em Fortaleza (CE).
} 


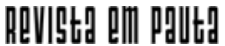

\} AUTONOMIA FEMININA E CONCEPÇÕES DE DIREITO - MARIANO, S.; SOUZA, M. F. \}

DOI: $10.12957 /$ REP.2019.45220

no Brasil, justificam a escolha por essas duas cidades e a tentativa de apreender as possíveis variações quanto às liberdades e capacidades - no sentido adotado por Amartya Sen (2008) e Martha Nussbaum (2002) - dessas mulheres em situação de pobreza. Essas capacidades são constituídas e constitutivas do contexto material e social no qual essas mulheres se inserem.

Para este momento em particular, temos como objetivo, por um lado, compreender as percepções dessas mulheres em torno de concepções políticas como direito e cidadania, com o intuito de inferir o modo como elas interpretam a relação com o Estado, o acesso às políticas públicas e o seu agenciamento nesse processo. Por outro lado, objetivamos captar e dimensionar a autonomia dessas mulheres para a tomada de decisões no espaço doméstico e em aspectos relativos à individualização feminina, tanto no contexto das relações familiares como das relações sociais mais amplas.

\section{Proteção social e autonomia feminina}

O campo das políticas públicas, e particularmente das políticas sociais, apresenta-se como área estratégica para a compreensão da estratificação e das desigualdades sociais. Conforme destaca Virginia Guzmán (2000, p. 85), "o estudo das políticas públicas é um terreno privilegiado para analisar as relações do Estado com os diversos atores sociais, entre eles as mulheres e, consequentemente, um bom indicador do grau de democratização da sociedade". Esta temática de investigação opera, portanto, com as intersecções entre a politização das relações de gênero, democratização social e redução das desigualdades sociais.

O tema da proteção social tem claro conteúdo político, o que envolve conflitos e contradições. Assim, o relativo consenso sobre a associação entre direitos sociais e cidadania não elimina as divergências em relação às formas de acesso e às responsabilidades que cabem ao Estado, à sociedade e à família, tendo em vista a garantia de proteção aos indivíduos. Em consequência, o conjunto das políticas representa diferentes níveis de consolidação dos direitos sociais. Essa problemática é especialmente percebida nas ações de combate à pobreza, para a qual o Programa Bolsa Família desempenha papel especial, no caso brasileiro.

Estamos de acordo com Sonia Alvarez (1988, p. 318) ao identificar que "a desigualdade com base em gênero está embutida na própria estrutura do poder estatal no Brasil", o que constitui um dos desafios para a democracia no país. "O Estado moderno não (é) neutro com relação a questões de gênero", o que se verifica, por exemplo, na representação que faz sobre a divisão entre as esferas "pública" ou política e a "privada" (ALVAREZ, 1988, p. 318). "Ele também institucionaliza as relações de poder genérico ao restringir o gênero feminino à última esfera, reforçando politicamente os limites que têm confinado a mulher social e historicamente" (ALVAREZ, 1988, p. 


\section{ReVl|sto am Pallt}

\} AUTONOMIA FEMININA E CONCEPÇÕES DE DIREITO - MARIANO, S.; SOUZA, M. F. \}

DOI: $10.12957 /$ REP.2019.45220

319). Por outro lado, ainda em concordância com a autora, o Estado não é uma instância monolítica quanto ao gênero, o que torna relevantes as pesquisas sobre as correlações de força, bem como as brechas no interior das instituições estatais.

Na outra ponta da problemática que nos interessa, os estudos sobre a pobreza, pelo menos desde as influências de Amartya Sen (2008), se depararam com a exigência de se perceber que os pobres são diferentes entre si, isto é, sendo a pobreza um fenômeno multidimensional, não é possível que seja examinada em termos genéricos, sem tratar devidamente sua diversidade e pluralidade. A questão fundamental abordada por Sen (2008), de nosso ponto de vista, é a chamada "perspectiva da capacidade", cuja principal formulação é de avaliar a pobreza não apenas como insuficiência de renda, mas por meio das capacidades individuais para realizar alguns funcionamentos básicos. A perspectiva da capacidade conecta-se diretamente com os temas do direito e da cidadania.

As concepções de direito e de cidadania são fundantes e fundadoras de concepções de sujeitos e, por consequência, de sujeitos de direitos, o que toma forma concreta na vida das pessoas, por exemplo, por meio dos tipos de políticas públicas que são formuladas para diferentes agrupamentos sociais (BONACCHI; GROPPI, 1995). Na esteira de concepções sexuadas de cidadania, políticas públicas igualmente sexuadas são forjadas. Como resultado, os referenciais sociopolíticos fundados em concepções de gênero engendram os tipos e os objetivos das políticas promovidas pelo Estado. Alimenta-se, assim, a necessidade de uma agenda de pesquisa feminista que se interrogue sobre a forma como concepções sociais de gênero se interconectam com enfoques de políticas, bem como se interroga sobre a forma como as ações estatais (re)produzem ou alteram as relações sociais de gênero, com possíveis impactos para a cidadania das mulheres, tendo em vista modificações, ou não, no grau de autonomia vivenciado pelas mulheres.

Pesquisas empíricas realizadas em diferentes contextos nos países ocidentais têm constatado a persistente associação entre, de um lado, direitos associados ao trabalho como políticas dirigidas a homens, e, de outro, direitos de assistência social como políticas dirigidas a mulheres (FRASER, 1999; PATEMAN, 2000). Operando com o mesmo registro, esse sistema de gênero embaraça as políticas dirigidas às mulheres com políticas dirigidas à família, subsumindo, assim, os interesses das mulheres aos interesses da família. Isso resulta, portanto, em políticas familistas (JELIN, 2004) ou políticas maternalistas (MOLYNEUX, 2007). Familismo e maternalismo têm como ponto comum a subordinação dos temas relativos à autonomia das mulheres às preocupações com o combate à pobreza, o bem-estar das famílias e o desenvolvimento. Nosso objeto se constitui, portanto, nas interconexões de temas como desigualdade, pobreza, desenvolvimento e gênero.

Tendo em vista tais interconexões, a autonomia das mulheres e, por conseguinte, os direitos e a cidadania das mulheres, devem ser tratados 


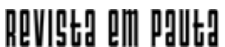

\} AUTONOMIA FEMININA E CONCEPÇÕES DE DIREITO - MARIANO, S.; SOUZA, M. F. \}

DOI: $10.12957 /$ REP.2019.45220

tendo-se em consideração os contextos particulares de experiência. Nesse caso, mulheres em situação de pobreza que vivem em áreas urbanas de grandes cidades brasileiras. Alijadas de modo mais pronunciado das esferas da política, especialmente pelas condições de gênero, de classe e de raça/ cor, a situação de receptora de benefícios assistenciais tende a constituir um canal de conexão entre essas mulheres pobres e o Estado, entendido por nós como ator fundamental para o reconhecimento e ampliação da cidadania das mulheres.

A reflexão sobre uma concepção teórica do Estado e sua importância para a cidadania das mulheres encontrou em algumas feministas contribuições efetivas que desafiam o mundo da política no sentido de garantir a cidadania plena às mulheres. Carole Pateman (2010), por exemplo, ainda que reconhecendo que consideráveis avanços se efetivaram na posição econômica das mulheres e na sua situação política, jurídica e cívica ao longo do século XX, questiona se podemos pensar em nossos dias nas mulheres como cidadãs plenas de direito em todos os países do mundo.

Contudo, conforme argumenta a autora, cabe responder tal questão à luz do que se entende por "cidadania plena". Se, em nossos tempos, a concepção de sufrágio universal não se presta mais a controvérsias, outros obstáculos estão colocados, tais como o da baixa representação política das mulheres e o da pobreza. Pateman (2010, p. 33) lembra que "a pobreza constitui um problema para a cidadania tanto dos homens como das mulheres, mas estas tendem a estar entre os mais pobres dos pobres".

Nas reflexões de Sonia Alvarez (2004), encontramos uma leitura acerca dos desafios enfrentados pelas feministas em relação ao Estado no que diz respeito à promoção da igualdade de gênero e, consequentemente, do exercício da cidadania plena. Neste sentido, Alvarez (2004) destaca três ordens de desafios: (a) institucional, tendo em vista a construção de instrumentos de políticas públicas e organismos institucionais aptos a fortalecer a cidadania das mulheres e, por conseguinte, a promoção e implementação de políticas que promovam melhores condições de vida para as mulheres e o enriquecimento de sua "cidadania empobrecida" (ALVAREZ, 2004, p. 104); (b) histórico-culturais, que dizem respeito aos aparentes impasses institucionais em nível local; e (c) político-culturais, relacionados às práticas, políticas e estratégias discursivas que podem e poderiam superar alguns dos impasses enfrentados pelas mulheres.

Do ponto de vista histórico, faz-se importante ressaltar que o sistema de proteção social brasileiro se pautou pela tradição e conservadorismo de caráter assistencialista, de bases filantrópicas e vínculos religiosos (MESTRINER, 2001). A efetivação de políticas públicas de assistência social, por parte de iniciativas do Estado, torna-se um grande desafio para a formação de um novo padrão cultural sobre a assistência social, tendo em vista planos de ação para uma política de proteção social efetivada diretamente pelo 


\section{ReVl|sto am Pallt}

\} AUTONOMIA FEMININA E CONCEPÇÕES DE DIREITO - MARIANO, S.; SOUZA, M. F. \}

DOI: $10.12957 /$ REP.2019.45220

Estado, apta a romper com o caráter fragmentado e mediador de organizações da sociedade civil (MARIANO, 2010).

Ao analisar a família como fator de proteção social, Goldani (2002) mostra a absorção por parte da família de maiores responsabilidades diante da fragilidade das ações estatais, amortizando o impacto das políticas econômicas e da reestruturação capitalista sobre o mercado de trabalho. Para a democratização da família, do nosso ponto de vista, é importante que as políticas sociais tenham como objetivo a maior autonomia dos indivíduos e não o objetivo de se beneficiar das funções protetoras da família, desempenhadas notadamente pelas mulheres, as quais reduzem as necessidades de investimentos públicos. Conforme sintetiza Martha Nussbaum (2002), essa mudança requer políticas de desenvolvimento que superem a lógica de tomar as mulheres "com fim dos outros" em benefício da adoção do princípio de que as mulheres são "um fim em si mesmas".

Em artigo anterior (MARIANO; SOUZA, 2015), analisamos as condições enfrentadas pelas mulheres titulares do PBF no que diz respeito à conciliação entre trabalho remunerado e cuidados familiares. Chamamos atenção para os obstáculos existentes a essa conciliação e os possíveis impactos positivos e negativos para a situação dessas mulheres, com vistas à redução das desigualdades de gênero. Apontamos para as dificuldades dessas mulheres quanto ao compartilhamento de tarefas de cuidados domésticos com outros membros familiares e o aumento das responsabilidades em decorrência das condicionalidades do PBF, conforme suas percepções.

Como desdobramento dessas dificuldades, destacamos as tensões vivenciadas por essas mulheres. Tensões essas que corroboram a crítica ao enfoque do bem-estar na orientação das políticas públicas. Um ponto a se destacar está centrado no fato de que a presença do cônjuge reduz as decisões das mulheres no espaço doméstico e em aspectos de sua individualização em quase todos os itens de respostas pesquisados. Os dados da pesquisa demonstram, ainda, que a presença do cônjuge é uma variável que interfere negativamente na participação das mulheres no trabalho remunerado.

Pesa, na opinião dessas mulheres, o fato de que as condicionalidades estabelecidas pelo PBF geram um trabalho adicional, aumentando assim suas obrigações. As mulheres são as responsáveis pelo pleito do benefício, por sua administração e pelo cumprimento das condicionalidades. Seguindo a lógica da "naturalização de gênero", é também sobre elas que pesam as "obrigações de caráter afetivo relacionadas à superação de condições de conflito, consideradas como 'desajustadas' ou 'desestruturadas'" (MARIANO, 2010, p. 43). Exige-se, portanto, trabalho material e subjetivo da parte das mulheres, sem qualquer correspondente quanto às exigências dirigidas aos homens, sendo que estas são quase nulas. 


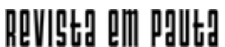

\} AUTONOMIA FEMININA E CONCEPÇÕES DE DIREITO - MARIANO, S.; SOUZA, M. F. \}

DOI: $10.12957 /$ REP.2019.45220

\section{Autonomia feminina nos contextos materiais e sociais pesquisados}

Ao adotar as contribuições feministas, pensamos a autonomia das mulheres em duas dimensões: social e política. Pesquisa realizada por Inglehart e Norris (2003), com base em dados internacionais, aponta para uma tendência global de crescimento dos valores associados à igualdade de gênero, especialmente entre mulheres com mais anos de escolaridade e menos religiosas. Tal processo está associado a mudanças culturais decorrentes da modernização, com destaque para as sociedades urbanas.

A despeito das críticas às teorias da modernização, estudos de Inglehart e Norris (2003) atestam que os valores associados à maior igualdade entre homens e mulheres estão mais presentes nas sociedades de maior desenvolvimento econômico e com melhores índices de desenvolvimento humano, e chegam, inclusive, a tomar o desenvolvimento humano como causa para mudanças culturais de atitudes que colaboram para maior igualdade de gênero. Se a questão do desenvolvimento humano pode parecer relativamente abstrata, ela toma concretude na qualidade dos direitos disponíveis a uma população e na percepção que essa população tem sobre esses direitos. Neste trabalho, operacionalizamos a noção de cidadania tendo como referência as percepções das mulheres sobre seus direitos e analisamos os tipos de direitos considerados mais importantes pelas entrevistadas, suas interpretações sobre o grau de respeito ou desrespeito a esses direitos, bem como os fatores por elas associados à garantia de direitos.

O Gráfico 1 apresenta informações acerca da percepção das entrevistadas sobre direitos. A questão sobre "qual é o direito de maior importância", conduzida às entrevistadas, nos possibilita captar as noções de direito entre essas mulheres, independentemente de esse direito ser real ou fictício. As beneficiárias, predominantemente, associam os direitos que consideram mais importantes às políticas sociais: saúde e educação destacam-se nas duas cidades pesquisadas. Fortaleza apresenta a vantagem de um índice maior de resposta. Em Curitiba, mais de $1 / 4$ não respondeu à questão. Por outro lado, das que responderam, o rol é mais variado, em comparação com Fortaleza.

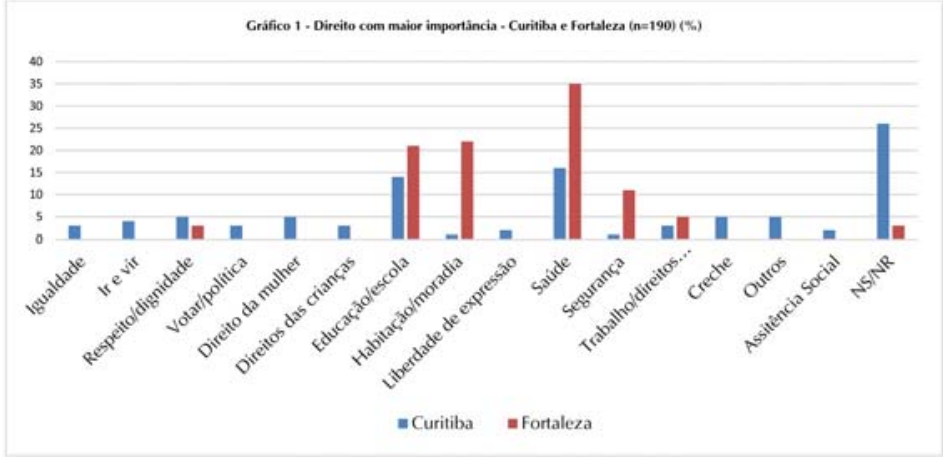




\section{ReVIIStg am PDUtI}

\} AUTONOMIA FEMININA E CONCEPÇÕES DE DIREITO - MARIANO, S.; SOUZA, M. F. \}

DOI: $10.12957 /$ REP.2019.45220

No contexto de pobreza urbana no Brasil, as preocupações dessas mulheres com direitos à saúde, à educação e à moradia, dizem respeito, notadamente, às necessidades femininas em relação aos serviços disponíveis para as filhas e filhos. Portanto, trata-se, preponderantemente, de interesses formulados a partir da própria estruturação das relações de gênero, o que indica dificuldades para a individualização das mulheres em situação de pobreza. O reconhecimento das mulheres com o status de indivíduo é condição necessária, ainda que não seja suficiente, para a autonomia feminina, consideradas as relações políticas, familiares e de trabalho.

Essas percepções também expressam um tipo de queixa à insuficiência dessas políticas sociais. O caso da sociedade brasileira é exemplar para se refletir sobre os obstáculos que as desigualdades, incluídas aí as de gênero, produzem para o desenvolvimento. Diante de um quadro histórico persistente de profundas desigualdades, os benefícios do desenvolvimento tendem a favorecer os grupos mais bem posicionados na hierarquia social, muitas vezes detentores de privilégios sociais, econômicos e políticos.

E o que acontece quando, para além da afirmação abstrata da igualdade de gênero na política, olhamos para outras dimensões constitutivas das relações entre homens e mulheres? Com base em survey nacional, realizado em 2003, sobre gênero, trabalho e família no Brasil, Clara Araújo e Celi Scalon (2006) constataram a presença de ambiguidades da esperada modernização no Brasil. Por um lado, há a presença de valores indicativos de relações de gênero mais igualitárias, como, por exemplo, a aceitação do trabalho feminino e a concordância quanto à necessidade de maior participação dos homens com os filhos e nas atividades domésticas. Por outro lado, persiste o entendimento de que a casa e a maternidade são centrais para a vida das mulheres, indicadores da "forte influência do tradicional modelo dual 'homem provedor' e 'mulher cuidadora'" (ARAÚJO; SCALON, 2006, p. 50).

Tais percepções compõem nosso quadro analítico e entendemos que a autonomia das mulheres envolve tanto as percepções relativas à vida pública como as relativas à vida privada. Cotejando-se os resultados encontrados por Araújo e Scalon (2006) e por Bohn (2008), constata-se que na sociedade brasileira os valores associados à igualdade de gênero, logo, também aos direitos, estão mais presentes nas percepções sobre a política formal do que nas percepções sobre família e cuidado. As percepções sobre direitos, entre as mulheres que participaram da nossa pesquisa, expressam parte desses significados, quando questões relativas à família e ao cuidado transbordam em suas preocupações.

Ao dar ênfase em saúde, educação e moradia, essas mulheres tomam uma necessidade como "direito", o que é uma percepção distinta da afirmação de que esses direitos sejam reais. Para não confundir "direito de jure" com "direito de fato" (BAUMAN, 2001), buscamos identificar entre as entrevistadas também suas percepções quanto ao grau de respeito aos direitos 


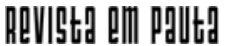

\} AUTONOMIA FEMININA E CONCEPÇÕES DE DIREITO - MARIANO, S.; SOUZA, M. F. \}

DOI: $10.12957 /$ REP.2019.45220

que elas consideram importantes (Gráficos 2 e 3). Predominantemente, nas duas cidades as entrevistadas avaliam que há desrespeito ou respeito parcial aos seus direitos. A saúde é o direito mais desrespeitado. Apesar do baixo índice, a educação é um dos poucos direitos com algum grau de respeito, ainda que seja de apenas $4 \%$ das respostas, também nas duas cidades.
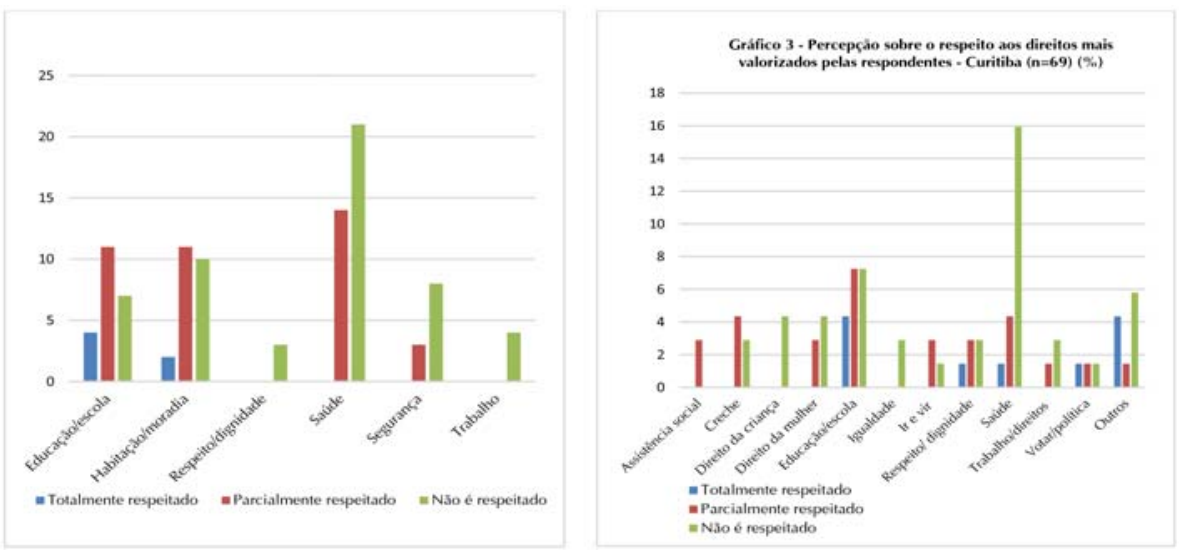

Esta percepção sobre os direitos desrespeitados deve ser interpretada positivamente, considerando sua potencialidade para a crítica ao contexto material, social e político da experiência das mulheres em situação de pobreza. Por outro lado, revela, paradoxalmente, os limites para a ampliação das oportunidades e das liberdades dessas mulheres. Essa ampliação é o centro normativo da teoria que tomamos de empréstimo de Martha Nussbaum (2002) para problematizar o empoderamento das mulheres em termos feministas.

Nossos dados permitem o entendimento de que os direitos sociais têm presença relevante nas percepções dessas mulheres, o que certamente é um elemento positivo, especialmente considerando o grau de privação, inclusive de natureza política, entre a população brasileira em situação de pobreza (DEMO, 2003). Entretanto, chama atenção o silêncio delas em relação aos demais direitos, mesmo os clássicos, como civis e políticos.

Em Curitiba, esses direitos são algumas vezes mencionados: igualdade; direito de ir e vir; respeito e dignidade e direito de votar são relacionados, mesmo com menor frequência. Entre o rol de respostas mais diversificadas em Curitiba, aparecem também "direitos da mulher", "direitos das crianças" e "creches". Esses são fatores que indicam certa politização dos direitos entre essas mulheres em ambas as cidades, com maior diversidade em Curitiba.

A politização dos direitos é um importante fator para o empoderamento das mulheres, tomado em sua dimensão coletiva; contudo, são 


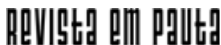

\} AUTONOMIA FEMININA E CONCEPÇÕES DE DIREITO - MARIANO, S.; SOUZA, M. F. \}

DOI: $10.12957 /$ REP.2019.45220

suscetíveis aos paradoxos fundados nas desigualdades políticas no Brasil. Esses paradoxos estão expressos na percepção das entrevistadas sobre as condições necessárias para a concretização dos direitos (Gráfico 4).

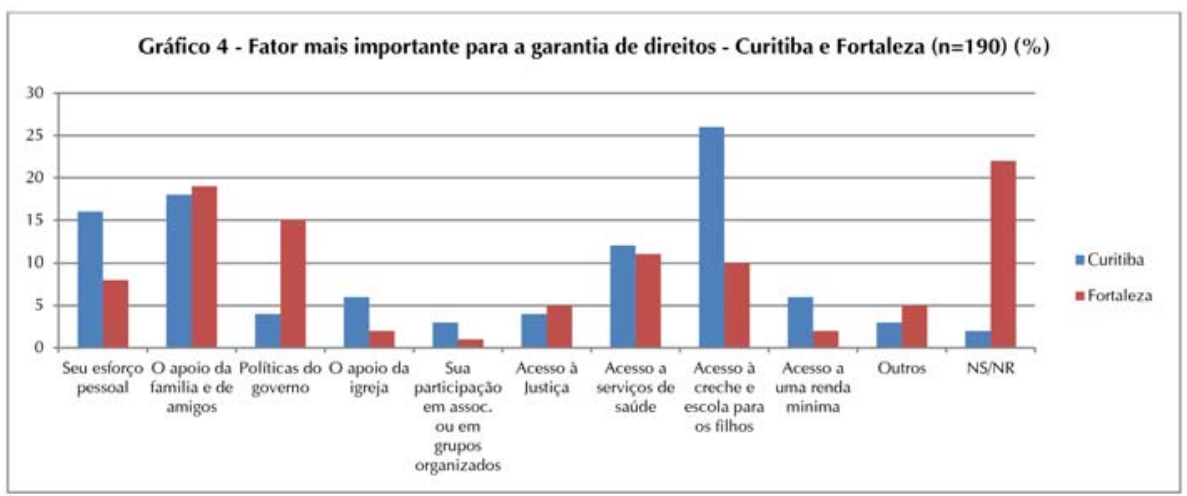

Desta vez são as entrevistadas de Fortaleza que apresentam um alto índice sem respostas, com $22 \%$. Nosso particular interesse com essa pergunta é tratar da agência dessas mulheres juntamente com a politização dessa agência, dimensões constitutivas do empoderamento. Conciliar agência e politização sobre os processos sociais é um modo de escapar do risco de tratar a agência em uma dimensão individualizada ou atomizada.

Ao tratar da pergunta sobre o fator que consideram mais importante para a garantia de seus direitos, as entrevistadas invocam tanto o acesso a serviços e políticas públicas quanto as formas de ação para a satisfação de suas necessidades. No primeiro caso, destaca-se, em Curitiba, a consciência de que o acesso aos serviços de creche é um fator importante para que essas mulheres assegurem seus direitos (26\%). Em Fortaleza, essa percepção é também expressiva (10\%). Compreender essas percepções só é possível levando-se em conta o contexto das políticas de educação infantil no Brasil, que responsabilizam as mulheres pelos cuidados e naturalizam essa responsabilidade, resultando em baixa cobertura do serviço mais diretamente afeito às tarefas reprodutivas que impactam o cotidiano das mulheres, especialmente daquelas que vivem em situação de pobreza nos grandes centros urbanos.

Quanto às formas de ação, o apoio da família e dos amigos, o esforço pessoal e o apoio das igrejas somam $40 \%$ das respostas em Curitiba e $29 \%$ em Fortaleza. O principal contraste ocorre entre "o esforço pessoal" (16\% em Curitiba e $8 \%$ em Fortaleza) e "políticas do governo" (4\% em Curitiba e 15\% em Fortaleza). A atuação do Estado tem maior peso para os direitos das mulheres pobres em Fortaleza, enquanto o protagonismo individual é mais presente nas percepções políticas em Curitiba. O apoio da família e dos amigos tem peso semelhante nas percepções das entrevistadas 


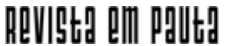

\} AUTONOMIA FEMININA E CONCEPÇÕES DE DIREITO - MARIANO, S.; SOUZA, M. F. \}

DOI: $10.12957 /$ REP.2019.45220

e, em contraste, o ativismo político é praticamente intocado, com $1 \%$ em Fortaleza e 3\% em Curitiba.

O poder de tomar decisão é um dado sensível para a autonomia das mulheres, especialmente em uma sociedade de estrutura patriarcal, como é o caso brasileiro (SARDENBERG, 2009). Os dados referentes ao poder de tomar decisão, por parte das entrevistadas, são apresentados no Gráfico 5, a seguir.

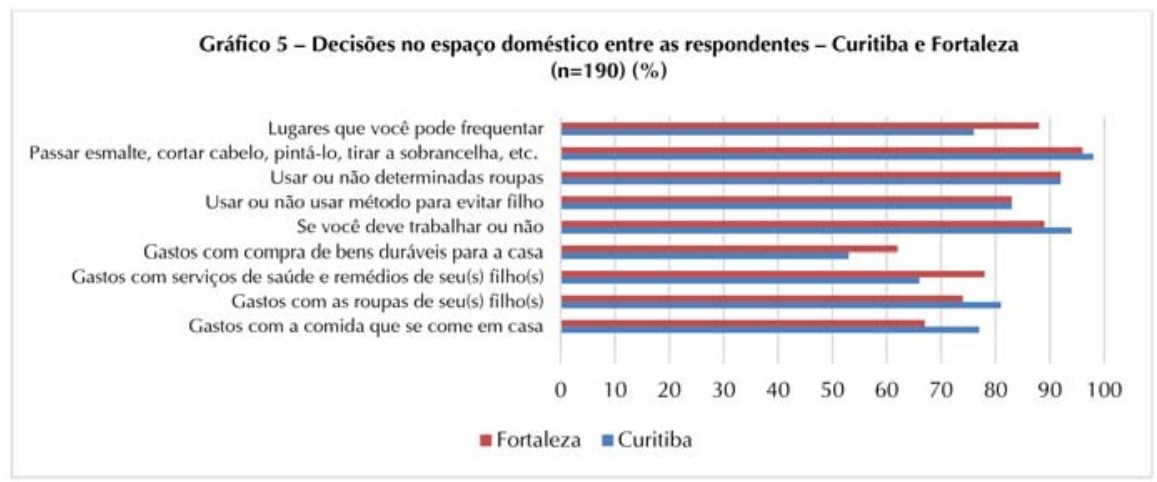

Carloto e Mariano (2012), em pesquisa com a realização de grupos focais com mulheres titulares do PBF em Londrina, Paraná, encontraram frequentemente os relatos que associavam as mudanças de vida advindas com o programa especialmente na esfera do consumo. Ao mesmo tempo, nesses grupos focais as mulheres relataram, com certa padronização, as experiências de restrições de suas liberdades individuais. Isso acontecia pela imposição da autoridade de diferentes homens nas relações de parentesco, sendo mais frequentemente a do cônjuge, pai e irmãos.

De início, tínhamos a estimativa de encontrar resultados semeIhantes na pesquisa que realizamos em Curitiba e Fortaleza. Entretanto, ao adotar o método de entrevistas individuais, obtivemos altas taxas de declaração de tomada de decisões em variados campos das liberdades individuais femininas, como a liberdade de decidir sobre os lugares que frequentam, o tipo de roupa que usam e o uso de recursos estéticos, como, por exemplo, maquiagem. Por outro lado, é elucidativo que os direitos reprodutivos sejam o de menor índice, ainda que seja relativamente alto, 83\% nas duas cidades. No campo do consumo, o item apresentando com menor capacidade de decisão das mulheres é a compra de bens duráveis, poder para o qual concorrem as condições de classe social.

Para tentar depurar um pouco essas variações entre os resultados encontrados por meio dos grupos focais e das entrevistas individuais, selecionamos apenas as respondentes com cônjuge (Gráfico 6). Isso porque os resultados dos grupos focais indicam que a presença do cônjuge é o 


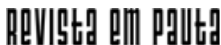

\} AUTONOMIA FEMININA E CONCEPÇÕES DE DIREITO - MARIANO, S.; SOUZA, M. F. \}

DOI: $10.12957 /$ REP.2019.45220

principal fator inibidor da autonomia feminina no que se refere às decisões assumidas por elas.

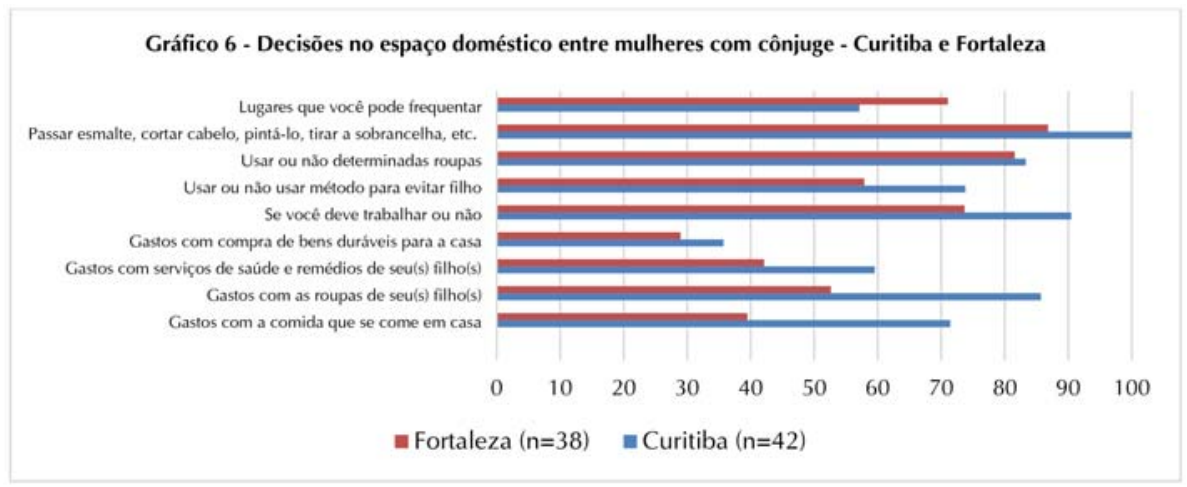

A presença do cônjuge reduz as decisões das mulheres no espaço doméstico em quase todos os itens de respostas, com um peso negativo mais acentuado em Fortaleza. Em Curitiba, 44\% das entrevistadas têm cônjuge e, em Fortaleza, são 40\%.

De acordo com os dados, há maior valorização da individualidade das mulheres entre as entrevistadas de Curitiba, o que, considerando a teoria da modernização revisitada, pode ser decorrente de algumas vantagens do contexto curitibano, em comparação com Fortaleza. Dentre essas, destacamos: maior presença de jovens; anos de estudo mais elevados, apesar da ainda baixa escolaridade entre essas mulheres em situação de pobreza nas duas capitais; maior taxa de ocupação em atividades remuneradas; maior acesso às vagas de creches para crianças; e menor presença de mulheres negras.

\section{Considerações finais}

Neste trabalho, a noção de autonomia feminina, como expressão do empoderamento das mulheres, é operacionalizada com base na capacidade de decisão e meios de liberdade demonstrados pelas entrevistadas. De modo sintético, destacamos os seguintes resultados: e "direito de fato";

1. As entrevistadas identificam a distância entre "direito de jure"

2. A ênfase das entrevistadas nos direitos associados às políticas públicas, especialmente aos direitos sociais, assim como a crítica à qualidade dessas políticas, indicam certa politização dos direitos entre essas mulheres, em ambas as cidades, com maior diversidade em Curitiba, cidade em que o rol de direitos citados é mais amplo; 


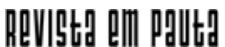

\} AUTONOMIA FEMININA E CONCEPÇÕES DE DIREITO - MARIANO, S.; SOUZA, M. F.

DOI: $10.12957 /$ REP.2019.45220

3. Os direitos mais valorizados pelas entrevistadas são predominantemente formulados a partir da estruturação dos papéis de gênero e são indicadores das dificuldades para a individualização das mulheres;

4. No que se refere às condições necessárias para a garantia dos direitos que as entrevistadas consideram importantes, ocorre um contraste entre "o esforço pessoal" (16\% em Curitiba e $8 \%$ em Fortaleza) e "políticas do governo" (4\% em Curitiba e 15\% em Fortaleza). A atuação do Estado tem maior peso para os direitos das mulheres pobres em Fortaleza, enquanto o protagonismo individual é mais presente nas percepções políticas em Curitiba. Nas duas cidades há pouquíssimas menções ao ativismo político.

As mulheres em situação de pobreza em Curitiba exibem mais elementos de individualização, com o risco de que essa individualização assuma também uma forma de atomização. Já em Fortaleza, as entrevistadas vinculam mais claramente seus direitos à capacidade de ação do Estado e circunscrevem a concepção de direitos especialmente às políticas sociais. Portanto, os significados de empoderamento e, consequentemente, os processos correspondentes, são variados nesses dois contextos, o que exige maior inventividade por parte de políticas que eventualmente se coloquem o objetivo de contribuir para o empoderamento das mulheres.

As pesquisas que levam em consideração as experiências singulares de determinados grupos de mulheres, como as mulheres em situação de pobreza em grandes centros urbanos, podem contribuir para maior refinamento das teses sobre persistências ou mudanças nos padrões de gênero. Como demonstrou Cynthia Sarti (2005a, 2005b), os valores morais entre famílias de trabalhadores urbanos (grande parte em situação de pobreza) associam a "ética do provedor" às responsabilidades masculinas, e as tarefas de dona de casa às responsabilidades femininas. Portanto, essa dualidade moral referida aos papéis tradicionais de gênero está fortemente marcada entre famílias das camadas populares.

Em termos gerais, as ambiguidades relativas às mudanças sociais no tocante à igualdade de gênero são, ainda, as principais marcas dos processos aqui refletidos. As mulheres em situação de pobreza exibem determinadas faixas de autonomia ou agenciamento, entretanto, revelam também a persistência de padrões tradicionais de gênero, como se constata, por exemplo, com o efeito negativo da presença do cônjuge para a autonomia individual dessas mulheres.

Desse modo, entendemos que os resultados gerados em nossa pesquisa podem contribuir para construções de modelos de análises que compreendam a pobreza em suas múltiplas dimensões. Isso significa que existem níveis diferenciados de pobreza que não a reduzem tão somente à desigualdade entre diferentes classes, mas também se expressam entre grupos em situação de pobreza, a exemplo das mulheres que aqui estudamos. Articular a dimensão da pobreza com a proteção social e a noção de empoderamento é um modo de enfrentamento da própria pobreza. 


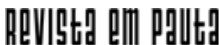

\} AUTONOMIA FEMININA E CONCEPÇÕES DE DIREITO - MARIANO, S.; SOUZA, M. F. \}

DOI: $10.12957 /$ REP.2019.45220

Empoderamento implica uma contínua dinâmica que exige aprimoramentos constantes. Para tanto, é importante que haja, por parte das políticas sociais, contínuas mobilizações de recursos como maneiras de intensificar estratégias de autonomia, do individual ao coletivo. Tais estratégias podem ser traduzidas em ações voltadas para (i) o envolvimento das mulheres no planejamento e avaliação das atividades afeitas ao PBF; (ii) o empreendimento de ações que tratem diretamente dos direitos das mulheres, assim como aquelas que contribuam para seu empoderamento social e econômico; (iii) a promoção de capacitação e provimento de recurso para o fortalecimento das aptidões sociais, políticas e econômicas das mulheres, especialmente aquelas capacidades que não se enquadram na tradicional divisão sexual do trabalho; (iv) a ampliação do acesso a políticas sociais referentes aos cuidados, notadamente educação infantil em período integral; (v) o incentivo ao retorno das mulheres adultas à escolarização; e (vi) o incentivo da participação dos homens em atividades do programa, quando apropriado.

Consequentemente, tais empreendimentos corroborarão para o incremento da autoestima das mulheres, mediante expansão das suas capacidades e estímulo ao acesso proativo de participação em movimentos da sociedade civil, envolvendo também suas famílias e os próprios homens. 


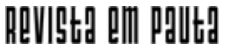

\} AUTONOMIA FEMININA E CONCEPÇÕES DE DIREITO - MARIANO, S.; SOUZA, M. F. \}

DOI: $10.12957 /$ REP.2019.45220

\section{Referências}

ALVAREZ, S. E. Politizando as relações de gênero e engendrando a democracia. In: STEPAN, A. (org.). Democratizando o Brasil. Rio de Janeiro: Paz e Terra, 1988.

ALVAREZ, S. Falas do Estado ou o estado das falas sobre as mulheres nas administrações democrático-populares. In: GODINHO, T.; SILVEIRA, M. L. (org.). Políticas públicas e igualdade de gênero. São Paulo: Coordenadoria Especial da Mulher, 2004.

ARAÚJO, C.; SCALON, C. Gênero e a distância entre a intenção e o gesto. Revista Brasileira de Ciências Sociais, v. 21, n. 62, 2006.

BAUMAN, Z. A modernidade líquida. Rio de Janeiro: Jorge Zahar Editores, 2001.

BOHN, S. R. Mulher para presidente do Brasil? Gênero e política na perspectiva do eleitor brasileiro. Opinião Pública, v. 14, n. 2, 2008.

BONACCHI, G.; GROPPI, A. (org.). O dilema da cidadania: direitos e deveres das mulheres. São Paulo: Ed. Unesp, 1995.

CARLOTO, C.; MARIANO, S. A. Empoderamento, trabalho e cuidados: muIheres no programa bolsa família. Textos e Contextos, Porto Alegre, v. 11, n. 2, 2012.

DEMO, P. Pobreza da pobreza. Petrópolis: Editora Vozes, 2003.

FRASER, N. A luta pelas necessidades: esboço de uma teoria crítica socialistafeminista da cultura política do capitalismo tardio. Debate Feminista, n. especial, 1999.

GOLDANI, A. M. Família, gênero e políticas: famílias brasileiras nos anos 90 e seus desafios como fator de proteção. Revista Brasileira de Estudos de População, v. 19, n. 1, jan./jun. 2002.

GUZMÁN, V. A equidade de gênero como tema de debate e de políticas públicas. In: FARIA, N.; SILVEIRA, M. L.; NOBRE, M. (org.). Gênero nas políticas públicas: impasses, desafios e perspectivas para a ação feminista. São Paulo: SOF, 2000.

INGLEHART, R.; NORRIS, P. Rising tide: gender equality \& cultural changes around the world. Nova York: Cambridge University Press, 2003.

JELIN, E. Pan e afectos - La transformación de las famílias. Buenos Aires: Fondo de Cultura Económica, 2004.

MARIANO, S. Cidadania sexuada feminina: a inclusão das mulheres na Política de Assistência Social. In: SOUZA, M. F. (org.). Desigualdades de gênero no Brasil: novas ideias e práticas antigas. Belo Horizonte: ARGVMENTVM Editora Ltda., 2010. 


\section{ReVIStg am p pdutg}

\} AUTONOMIA FEMININA E CONCEPÇÕES DE DIREITO - MARIANO, S.; SOUZA, M. F. \}

DOI: $10.12957 /$ REP.2019.45220

MARIANO, S.; SOUZA, M. F. Conciliação e tensões entre trabalho e família para mulheres titulares do Programa Bolsa Família. Revista Brasileira de Ciência Política, n. 18, 2015.

MESTRINER, M. L. O Estado entre a filantropia e a assistência social. São Paulo: Cortez Editora, 2001.

MOLYNEUX, M. Change and continuity in social protection in Latin America - mothers at the service of the State? Paper Gender and Development Programme, Geneva, n. 1, 2007.

NUSSBAUM, M. Las mujeres y el desarrollo humano: el enfoque de las capacidades. Barcelona: Herder Editorial, 2002.

PATEMAN, C. El Estado de bienestar patriarcal. Contextos, v. 2, n. 5, 2000.

PATEMAN, C. Garantir a cidadania das mulheres: a indiferença e outros obstáculos. Revista Crítica de Ciências Sociais, n. 89, 2010.

SARDENBERG, C. Conceituando "empoderamento" na perspectiva feminista. In: SEMINÁRIO INTERNACIONAL: TRILHAS DO EMPODERAMENTO DE MULHERES, 1., 2006, Salvador. Bahia: UFBA, 2009. Disponível em: http:// repositorio.ufba.br/ri/handle/ri/6848. Acesso em:

SARTI, C. A. A família como espelho: um estudo sobre a moral dos pobres. São Paulo: Cortez, 2005a.

SARTI, C. A. Famílias enredadas. In: ACOSTA, A. R.; VITALER, M. A. F. (org.). Família: redes, laços e políticas públicas. São Paulo: Cortez, 2005b.

SEN, A. Desigualdade reexaminada. Rio de Janeiro: Record, 2008.

DOI: $10.12957 /$ rep.2019.45220

Recebido em 08 de janeiro de 2019.

Aprovado para publicação em 23 de abril de 2019.

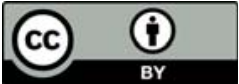

A Revista Em Pauta: Teoria Social e Realidade Contemporânea está licenciada com uma Licença Creative Commons Atribuição 4.0 Internacional. 